\title{
Defective Histamine Release in Chronic Urticaria
}

\author{
Frank Kern and Lawrence M. Lichtenstein \\ From the Johns Hopkins University School of Medicine at the Good \\ Samaritan Hospital, Baltimore, Maryland 21239
}

A B S T R A C T Histamine release from peripheral blood leukocytes challenged with anti-human $\operatorname{IgE}$ was studied in patients with chronic urticaria and nonatopic controls. 19 of 23 controls, but only 6 of 20 patients, released over $20 \%$ of the total available leukocyte histamine. The response to anti-IgE concentrations of 1.66 , $0.33,0.066$, and $0.013 \mu \mathrm{g}$ antibody $\mathrm{N} / \mathrm{ml}$ was significantly lower in patients than in controls. Serum $\operatorname{IgE}$ levels were significantly higher in the patients but total histamine content of about $10^{7}$ leukocytes was not. Deuterium oxide $\left(\mathrm{D}_{2} \mathrm{O}\right)$ greatly increased histamine release (in both groups), indicating that the anti-IgE interacted with the basophils of urticaria patients. Passive sensitization of leukocytes with biologically active $\mathrm{IgE}$ was achieved in both patients and control subjects whose cells responded to anti-IgE, but was not achieved in either patients or control subjects whose cells were nonresponsive to anti-IgE challenge. ${ }^{125} \mathrm{I}$-anti-IgE autoradiographic studies revealed no obvious quantitative abnormality in the amount of basophil-bound $\operatorname{IgE}$ in chronic urticaria patients. Ionophore stimulation of aliquots of the same leukocytes used for anti-IgE challenge demonstrated that the urticaria patients' basophils were capable of releasing normal amounts of histamine. Leukocyte cyclic AMP levels in the two groups were not significantly different either in base-line levels or in responsiveness to stimulation with isoproterenol. These data indicate that chronic urticaria patients have a (acquired?) defect in leukocyte histamine release that occurs after the anti-IgE-IgE interaction, but before the actual (second-stage) release process, and that is comparable to the phenomenon of desensitization.

This is publication no. 185, O'Neill Laboratories, The Good Samaritan Hospital.

Dr. Kern is the recipient of a Fellowship from the Society for Investigative Dermatology. Dr. Kern's present address is: 31B Wynnewood Road, Wynnewood, Pa. 19096.

Received for publication 22 September 1975 and in revised form 8 January 1976.

\section{INTRODUCTION}

Early in this century, several investigators demonstrated that histamine injected into skin resulted in signs and symptoms identical to those found in urticaria $(1,2)$, and that urticarial skin reactions could be effected by antibody-antigen interaction (3). Subsequently, it has generally been assumed that chronic urticaria represents an allergic reaction (4), even though the etiology of most cases cannot be determined. While various pharmacologic agents and mediators of inflammation can produce vasodilatation and increased capillary permeability (5-9), histamine produces the pruritus characteristic of this condition. Thus, urticaria is considered to be largely the result of localized histamine release within a circumscribed area of the skin. Current opinion holds that while every effort must be made to exclude an allergenic etiology, it seems probable that in the majority of chronic urticaria patients, antigen-IgE interactions are playing no part. If this view is correct, an understanding of the intracellular enzymatic and biochemical events controlling or leading to histamine release may result in better methods for control of urticaria, regardless of specific etiology. Recently, Greaves et al. (10) reported that the extent of basophil leukocyte histamine release caused by anti-human $\operatorname{IgE}$ (i.e., reversed in vitro anaphylaxis [11]) is significantly lower in chronic urticaria patients than in matched controls. The studies reported here were undertaken in an attempt to confirm these results and explore the nature of any demonstrated defect in histamine release found in urticaria patients.

\section{METHODS}

Subjects. 21 patients, 15 female and 6 male, with a history of chronic urticaria were referred for study. All reported at least weekly recurrences of transient lesions $(<48$ h). All had symptoms for over 6 wk with a mean duration of $36.3 \mathrm{mo}$ (range 2-168 mo). Ages ranged from 15 to 75 yr (average $37.7 \mathrm{yr}$ ). 12 patients were Caucasian and 9

The Journal of Clinical Investigation Volume 57 May 1976 1369-1377 
were Black. 4 patients were considered to be atopic on the basis of a personal history of seasonal pollinosis, asthma, and/or atopic dermatitis. 4 additional patients had a family history of one of these conditions. 13 patients used antihistamines, 1 patient used systemic corticosteroids, and 3 patients used both agents regularly as therapy for their urticaria. All urticaria patients had discontinued antihistamines and/or systemic corticosteroid therapy at least $48 \mathrm{~h}$ before blood collection. 5 patients had active lesions at the time of study. 24 subjects, 16 female and 8 male, who had never had urticaria, asthma, hay fever, or atopic dermatitis served as controls. 18 were Caucasian and 6 were Black. Their average age was also $37.7 \mathrm{yr}$. None were taking antihistamines or systemic corticosteroids. All blood collections were performed between 8 a.m. and 9 a.m.

Anti-human IgE. Rabbit anti-human IgE, produced by immunization with the $\mathrm{Fc}$ fragment of a human $\mathrm{IgE}$ myeloma protein and then absorbed with $\operatorname{IgE~Fab~fragments,~as~}$ previously described (12), was graciously supplied by Dr. Kimishige Ishizaka.

White blood cell and basophil counts. White blood cell counts were performed on EDTA-treated whole blood with a Coulter counter (model-S, Coulter Electronics, Inc., Hialeah, Fla.). Blood smears were observed after Wright's staining, and the number of basophils per 500 white cells was determined. Final results were calculated to give the number of basophils per milliliter of whole blood.

Anti-IgE-induced leukocyte histamine release. Histamine release from human leukocyte preparations was performed as previously described $(13,14)$. Briefly, $50 \mathrm{ml}$ of peripheral blood was drawn into a mixture of dextran, EDTA, and glucose. The cells were allowed to sediment at room temperature for approximately $90 \mathrm{~min}$, and the supernatant fluid containing plasma, platelets, and white blood cells was aspirated and centrifuged gently $(100 \mathrm{~g})$ to sediment the white blood cells, leaving the platelets in the fluid phase. The resulting pellet of white blood cells was washed twice in a Tris-saline buffer $(\mathrm{NaCl}, 120 \mathrm{mM} ; \mathrm{KCl}, 5 \mathrm{mM}$; Tris, 25 $\mathrm{mM}, \mathrm{pH} 7.4$, supplemented with $0.33 \%$ human albumin) (Tris-A) ${ }^{1}$ and suspended in the same buffer with added calcium $(0.6 \mathrm{mM})$ and magnesium $(1.0 \mathrm{mM})$ (Tris-ACM) at a concentration of approximately $10^{7} \mathrm{cell} / \mathrm{ml}$ (13). Aliquots of the cell suspension were delivered to tubes containing the appropriate concentration of anti-IgE and/or pharmacologic agents being studied, and histamine release was allowed to proceed for $60 \mathrm{~min}$ at $37^{\circ} \mathrm{C}$. Tubes were run in duplicate, and to ascertain spontaneous histamine release, each experiment contained cell aliquots to which only buffer was added. Each experiment also contained cell aliquots lysed in perchloric acid to determine the total histamine content. After incubation, reaction tubes were centrifuged, and the quantity of histamine released into the supernate was determined by a fluorometric method modified from that of Shore et al. (15). Histamine release less than $10 \%$ was not considered significant in these experiments, and these patients were defined as "unresponsive." Reproducibility of histamine release curves in two subjects is demonstrated in Fig. 1.

Deuterium oxide enhancement of anti-IgE-induced leukocyte histamine release. Tris-ACM made with deuterium oxide $(30 \% \mathrm{vol} / \mathrm{vol})$ and anti-IgE ( $0.333 \mu \mathrm{g}$ antibody N/ $\mathrm{ml})$ were added to aliquots of cells from 16 patients and

${ }^{1}$ Abbreviations used in this paper: PLA, phospholipase A ; Tris-A, Tris supplemented with human albumin; TrisACM, Tris-A with added calcium and magnesium.

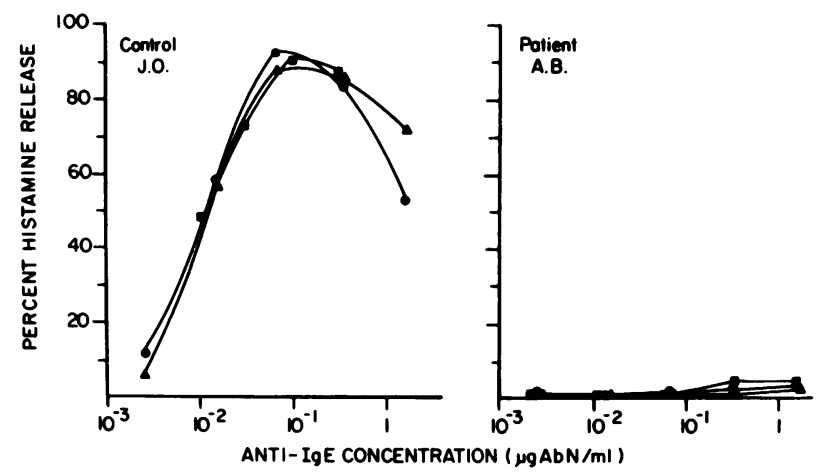

FIGURE 1 Leukocyte histamine release curves of a control subject and a patient with chronic urticaria. The three determinations for each subject were performed over a 10 -wk period and indicate the highly reproducible nature of the histamine release assay. $\mathrm{Ab}$, antibody.

13 control subjects, and the percent histamine released was determined similarly (16).

Calcium ionophore-induced leukocyte histamine release. Aliquots of the same cells used for anti-IgE-induced histamine release were incubated at $37^{\circ} \mathrm{C}$ for $60 \mathrm{~min}$ with the calcium ionophore A23187 in a final concentration of 6.66 $\mu \mathrm{g} / \mathrm{ml}$, and histamine release was determined (17).

Serum IgE concentration. Serum IgE protein was determined by a modification of the direct (noncompetitive binding) radioimmunosorbent test, as described by Wide (18). Briefly, sera were incubated with a suitable dilution of goat anti-human IgE antibody insolubilized to Sepharose 4-B (Pharmacia Fine Chemicals, Inc., Piscataway, N. J.) by the cyanogen bromide method. Dilutions of a reference serum of known IgE content (substandardized from WHO reference preparation numbers 68/341) were included in each assay to provide a standard curve. After $24 \mathrm{~h}$ of incubation at room temperature on an orbital rotator, the immunosorbent was washed and incubated for a second period of 16-24 $\mathrm{h}$ with ${ }^{125}$ I-labeled rabbit anti-Fce. After washing, bound radioactivity was counted and $\mathrm{IgE}$ content determined by reference to the standard serum. Results are expressed as international units (converted to nanograms by multiplying by 2.4 ).

Leukocyte cyclic AMP levels. Washed cell aliquots of the same preparations used in the anti-IgE-induced histamine release studies from 13 patients and 16 control subjects were incubated at $37^{\circ} \mathrm{C}$ for $20 \mathrm{~min}$ and then centrifuged. The cell pellet was then lysed with $5 \%$ trichloroacetic acid, and cyclic AMP determinations were carried out by the technique described by Brown et al. (19). Cell counts were performed on the washed cells and the cyclic AMP levels calculated per $10^{7}$ leukocytes.

Isoproterenol stimulation of leukocyte cyclic $A M P$. Washed cell aliquots of the same preparations used in the anti-IgE-induced histamine release studies from the 20 patients and 23 control subjects whose mean histamine release curves are shown in Fig. 2 were incubated at $37^{\circ} \mathrm{C}$ for $20 \mathrm{~min}$ with or without isoproterenol $(1.6 \mu \mathrm{mol})$ and then centrifuged. The cell pellet was then lysed with $5 \%$ trichloroacetic acid, and cyclic AMP determinations were carried out as noted above. Cell counts of the washed leukocytes were not performed, but each preparation served as its own control, in terms of changed cyclic AMP. 


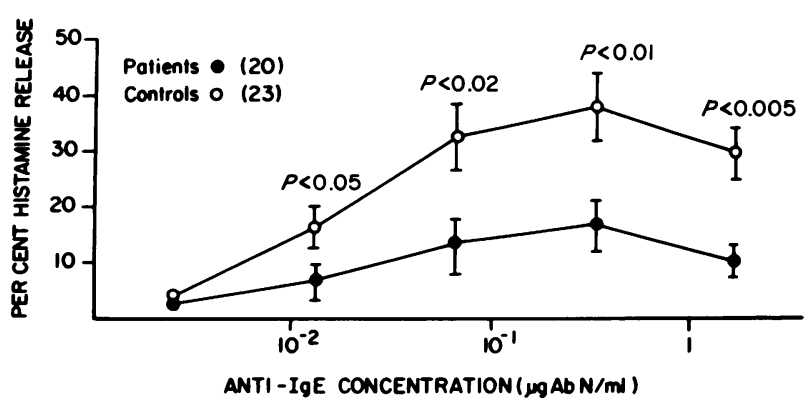

Figure 2 Histamine release curves of urticaria patients $(\bullet)$ and control subjects $(O)$. Brackets indicate the SEM and significance levels are shown. $\mathrm{Ab}$, antibody.

Passive sensitization studies. Passive sensitization of human leukocytes from 10 patients and 7 control subjects was performed as described by Levy and Osler (20). In these studies, the washed leukocytes were incubated with a 1:5 dilution (Tris-A) of serum with known biologically active IgE antibody against phospholipase A (PLA) (the main allergen in honey bee venom), in the presence of EDTA and heparin for $90 \mathrm{~min}$ at $37^{\circ} \mathrm{C}$. Cells were washed twice, resuspended in Tris-ACM, incubated with PLA for $45 \mathrm{~min}$, and histamine released was determined.

${ }^{125} I$-anti-IgE autoradiography. The method for basophil leukocyte autoradiography has been described (21). Briefly, $30 \mathrm{ml}$ of peripheral blood from each subject was drawn into a glass flask containing $1.5 \mathrm{ml}$ of $10 \%$ EDTA. 1 vol of the anticoagulated blood was mixed with 3 vol of normal saline, and $10 \mathrm{ml}$ of the suspension was layered over $3 \mathrm{ml}$ HypaqueFicoll mixture $(d=1.077)$ in a $13 \times 125-\mathrm{mm}$ tube. The tubes were centrifuged at $20^{\circ} \mathrm{C}$ for $40 \mathrm{~min}$ at a speed sufficient to produce approximately $450 \mathrm{~g}$ at the interface. The mononuclear cell layers containing the majority of the basophil leukocytes were collected and incubated at $0^{\circ} \mathrm{C}$ for $30 \mathrm{~min}$ with ${ }^{125}$ I-labeled anti-IgE in Tris-A buffer containing $0.01 \mathrm{M}$ EDTA (22). The cells were washed five times with the same buffer at $0^{\circ} \mathrm{C}$, and smears of the cells were then stained with Wright's stain. The stained slides were then coated with $0.8 \%$ celloidin dissolved in a mixture of absolute ethanol and ether. After drying, the slides were covered with Nuclear Track emulsion NTB 2 (Eastman Kodak Co., Rochester, N. Y.), and slides from each subject were developed after 24,48 , and $72 \mathrm{~h}$ and examined by light microscopy. The radioactive grains overlying identifiable basophil leukocytes (presence of metachromatic granules) and bounded by the cell's plasma membrane were counted (Table IV).

\section{RESULTS}

Mean basophil counts in our patients and control subjects averaged $0.8 \%$ of the white blood cells and were within normal limits in all subjects (Table I). The mean total serum IgE level was significantly higher in patients than in controls $(P<0.05)$, although the mean concentration was within normal limits in both groups. None of the control subjects were atopic, whereas four of the urticaria subjects had a personal history of asthma, seasonal pollinosis, and/or atopic dermatitis. If the serum $\operatorname{IgE}$ concentrations of atopic patients
TABLE I

Serum IgE Level and Basophil Counts

\begin{tabular}{lccc}
\hline & \multicolumn{2}{c}{ Serum IgE } & \\
\cline { 2 - 3 } & All & Nonatopic & Basophil counts \\
\hline \multirow{3}{*}{ Urticaria } & \multicolumn{2}{c}{$I U / m l$} & cells $/ m l$ \\
& $(21)$ & $(17)$ & \\
Control & $206 \pm 70$ & $147 \pm 47$ & $4.5 \pm 0.9 \times 10^{4}$ \\
& $(24)$ & $(24)$ & \\
$P$ & $38 \pm 8$ & $38 \pm 8$ & $5.6 \pm 0.6 \times 10^{4}$ \\
& $<0.05$ & $<0.05$ & NS
\end{tabular}

Values are means $\pm S E M$. Numbers of subjects are in parentheses.

are omitted from the calculations, the mean serum $\operatorname{IgE}$ levels of urticaria patients remains significantly higher $(P<.05)$ than controls (Table I).

The total histamine content of approximately $10^{7}$ white cells in patients and control subjects was not significantly different, although the cells of patients had slightly less histamine than those of the controls (Table II). Spontaneous release from the cells of both groups also did not differ significantly and was under $5 \%$ in all cases. However, if responders and nonresponders of both patient and control groups are considered separately, then significant differences in leukocyte histamine content are found (Table II) between responders and nonresponders as a whole $(P<0.05)$, and between responding controls and either nonresponding patients $(P<0.05)$ or controls $(P<0.05)$.

Five-point histamine release determinations with anti$\mathrm{IgE}$ were carried out on the isolated leukocytes of patients and control subjects. Typical results are shown in Fig. 1, which illustrates a control response and the complete lack of any histamine release with the cells obtained from a patient with chronic urticaria. The figure also illustrates the reproducibility of these findings: the three curves are from separate experiments carried out over $10 \mathrm{wk}$.

A summary of data obtained in patients and controls is shown in Fig. 2. At all concentrations of anti-IgE used, the mean histamine release from leukocytes of

TABLE II

Histamine Content

\begin{tabular}{lcllll}
\hline & Responders & Nonresponders & \multicolumn{2}{c}{ Total } \\
\hline & & \multicolumn{4}{c}{$n g / 10^{7}$ leukocytes } \\
A. Patients (11) & $111 \pm 42$ & B. (9) $69 \pm 16$ & C. $(20)$ & $92 \pm 24$ \\
D. Controls (19) & $148 \pm 33$ & E. (4) $68 \pm 11$ & F. (23) & $134 \pm 28$ \\
G. Total (30) & $135 \pm 26$ & H. (13) $69 \pm 12$ & & \\
\hline
\end{tabular}

Comparison of all possible groups reveals $B$ and $D, D$ and $E$, and $G$ and $H$ to be significantly different $(P<0.05)$. Values are means \pm SEM.

Histamine Release in Urticaria 

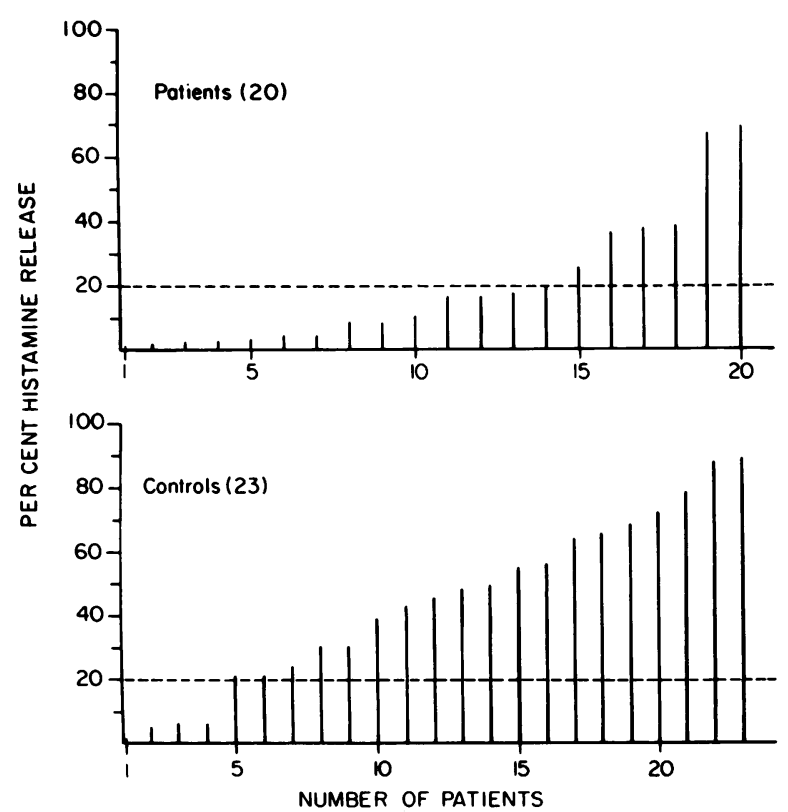

Figure 3 Maximum leukocyte histamine release in urticaria patients (upper) and control subjects (lower) at any antiIgE concentration tested.

patients with chronic urticaria was less than the mean histamine release of the control group. This difference was significant at anti-IgE concentrations of $1.66(P<$ $0.005), 0.33(P<0.01), 0.066(P<0.02)$, and $0.013(P$ $<0.05) \mu \mathrm{g}$ antibody $\mathrm{N} / \mathrm{ml}$. At each concentration, two to three times as many controls showed significant $(>10 \%)$ histamine release as patients, but there was overlap, with some patients releasing a high percentage of histamine, and some controls releasing little. This is graphically illustrated in Fig. 3, which indicates the maximum percent histamine release in all subjects at any anti-IgE concentration tested. Although 14 of 20 patients $(70 \%)$ release less than $20 \%$ of their total available leukocyte histamine, 4 of 23 controls (17\%) also release less than this amount. The mean histamine release of responding subjects $(>10 \%$ release) was lower in urticaria patients than in controls at all but the lowest anti-IgE concentration tested (Table III), indi- cating that the observed difference is not due solely to the presence of an increased incidence of nonresponsive leukocytes within the urticaria patients.

The addition of $\mathrm{D}_{2} \mathrm{O}$ increased $\mathrm{IgE}$-induced histamine release. The mean increase in percent histamine release caused by $\mathrm{D}_{2} \mathrm{O}$ was similar in patients $(15 \%)$ and controls $(16 \%)$. The percent histamine release with and without $\mathrm{D}_{2} \mathrm{O}$ is shown for each subject in Fig. 4. The striking finding in these experiments is that if the cells from a subject, whether patient or control, did not respond to anti-IgE (i.e., less than $10 \%$ histamine release), $\mathrm{D}_{2} \mathrm{O}$ did not change the lack of response, whereas if there was significant histamine release, $\mathrm{D}_{2} \mathrm{O}$ increased the response in most instances.

To study further the terminal events in the histamine release sequence, cells from patients and controls were challenged with the calcium ionophore A23187 at a dose known to produce a wide range of histamine release in most subjects (17). The mean percent histamine release produced by this agent was not significantly different in the two groups (value $\pm S D$ : control, $65 \pm 20 \%$; urticaria, $68 \pm 22 \%$ ).

The level of cyclic AMP in leukocyte preparations from patients and controls was determined to ascertain if there was a difference in base-line level or in responsiveness to beta adrenergic stimulation with isoproterenol. Base-line levels of leukocyte cyclic AMP were determined in 13 patients and 16 control subjects. Anti-IgE histamine release in this subset of original subjects was performed simultaneously. Special attention was given to those technical factors that might affect intracellular cyclic AMP levels, such as the subject's state of fasting, the time of day blood was collected, and time of cell sedimentation. While the mean histamine release curves of these patients and controls were significantly different at anti-IgE concentrations of $1.66(P<0.05), 0.33(P$ $<0.05), 0.066(P<0.05)$, and $0.03 \quad(P<0.02) \quad \mu \mathrm{g}$ antibody $\mathrm{N} / \mathrm{ml}$, the base-line cyclic AMP levels per $10^{7}$ cells were not (Table IV). Cell counts were not performed on the aliquots used for isoproterenol stimulation. Each set of cells served as its own control. The percentage increase of leukocyte cyclic AMP on iso-

TABLE III

Average Anti-IgE-Induced Histamine Release in Responding Subjects*

\begin{tabular}{|c|c|c|c|c|c|}
\hline & \multicolumn{5}{|c|}{ Anti-IgE Concentration ( $\mu \mathrm{g}$ antibody $\mathrm{N} / \mathrm{ml}$ ) } \\
\hline & 0.0026 & 0.013 & 0.066 & 0.333 & 1.666 \\
\hline & \multicolumn{5}{|c|}{$\%$ histamine release } \\
\hline Patients & (1) 19.6 & (4) 26.2 & (7) 34.6 & (9) 33.6 & (7) 22.8 \\
\hline Controls & (3) 16.2 & (10) 33.7 & (17) 43.7 & (17) 49.9 & (17) 37.5 \\
\hline
\end{tabular}

Numbers of patients are in parentheses.

* Over $10 \%$ histamine release. 


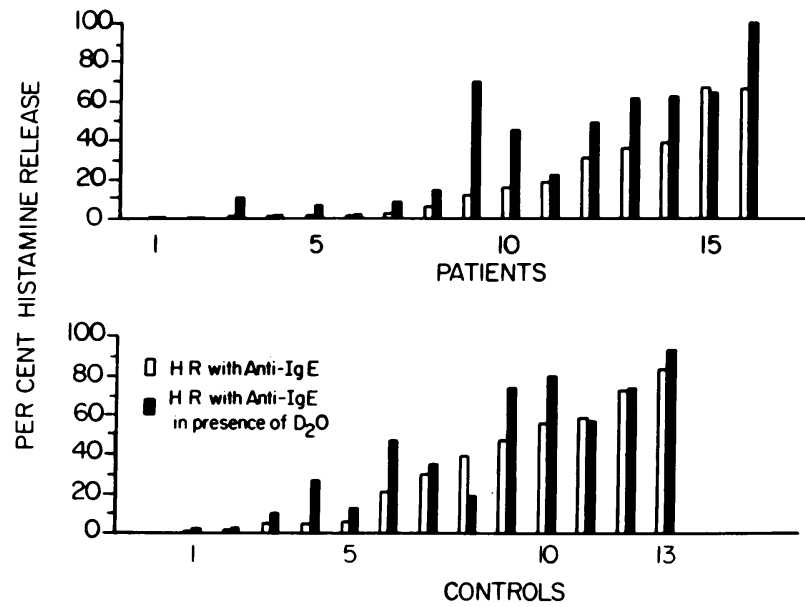

FIGURE 4 Deuterium oxide enhancement of anti-IgE leukocyte histamine release (HR). Each patient (upper) and control subject (lower) is represented by a pair of bars indicating leukocyte histamine release induced by anti-IgE at a concentration of $0.33 \mu \mathrm{g}$ antibody $\mathrm{N} / \mathrm{ml}$ with and without the presence of heavy water.

proterenol stimulation was similar in both groups (increase: patients, $494 \%$; controls, $456 \%$ ).

To determine whether decreased histamine release with anti-IgE is due to the absence of normal $\operatorname{IgE}$ in the patients with chronic urticaria, passive sensitization studies were performed with known biologically active $\mathrm{IgE}$ antibody against the main allergen in honey bee venom (PLA). $\mathrm{D}_{2} \mathrm{O}$ was included in the release medium to maximize the response. Subsequent antigeninduced histamine release revealed that no significant histamine release was demonstrable in any of the six patients or two controls who had had less than $10 \%$ histamine release with anti-IgE. However, the four patients and five control subjects who had more than $10 \%$ anti-IgE-induced histamine release did demonstrate significant PLA-induced histamine release after passive sensitization of their leukocytes (Fig. 5).

${ }^{125} \mathrm{I}-\mathrm{anti}-\mathrm{Ig} \mathrm{E}$ autoradiographic studies of the peripheral

TABLE IV

Base-Line Leukocyte Cyclic AMP Level

\begin{tabular}{lccc}
\hline & \multicolumn{3}{c}{ Cyclic AMP } \\
\cline { 2 - 3 } & \multicolumn{2}{c}{ Patients } & \multicolumn{1}{c}{ Controls } \\
\hline \multicolumn{4}{c}{ pmol/107 cells } \\
Responders & (7) $9.3 \pm 4.7$ & (12) $10.2 \pm 3.6$ & NS \\
Nonresponders & (6) $9.5 \pm 2.7$ & (4) $12.4 \pm 6.0$ & NS \\
$P$ & NS & NS & \\
Total & (13) $9.4 \pm 3.7$ & (16) $10.8 \pm 4.2$ & NS
\end{tabular}

Results are means \pm SD. leukocytes from three patients and one control subject were performed to determine if a gross quantitative defect in the basophil-bound $\operatorname{IgE}$ was responsible for the decreased anti-IgE-induced histamine release observed in urticaria patients. These subjects were chosen because leukocytes from the urticaria patients released less than $10 \%$ of their total available histamine in the histamine release studies, whereas the leukocytes of the control subject released over $70 \%$ of available histamine on anti-IgE challenge. Light microscopy revealed that basophils from the chronic urticaria patients and the control subjects bound significant quantities of labeled anti-IgE (Fig. 6). The average number of radioactive grains overlying 30 basophils from the urticaria patients and control subject is presented in Table $\mathrm{V}$.

14 subjects were reevaluated clinically and their antiIgE-induced leukocyte histamine release was tested approximately every 2 mo over $8-10$ mo. Five of the urticaria patients demonstrated significant clinical improvement over this period, and leukocyte histamine release during a period of relative quiescence in their disease revealed a dramatic increase in responsiveness (histamine induced by $0.33 \mu \mathrm{g}$ antibody $\mathrm{N} / \mathrm{ml}$ anti-IgE: active urticaria, $19,1,0,0$, and $8 \%$; quiescent period, 46,19 , 22,21 , and $74 \%$, respectively).

\section{DISCUSSION}

These studies were initiated in an attempt to gain some insight into the pathogenesis of chronic urticaria with the expectation that progress toward the control of this disease may be achieved by viewing the problem not as due to innumerable "specific etiologies," but rather

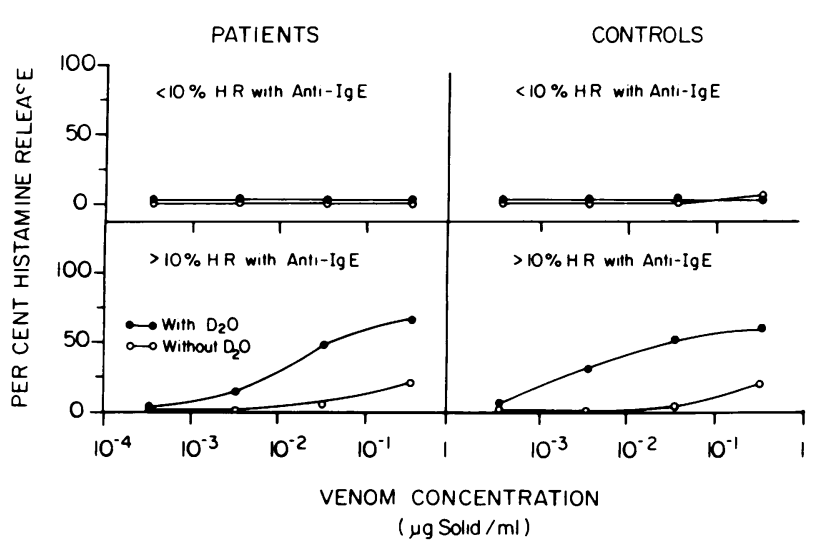

FIgURE 5 Histamine release (HR) induced by honey bee PLA in leukocytes from urticaria patients and control subjects passively sensitized to this antigen. The patient and control groups are each divicied into two subgroups dependent upon their leukocyte response to anti-IgE.

Histamine Release in Urticaria 

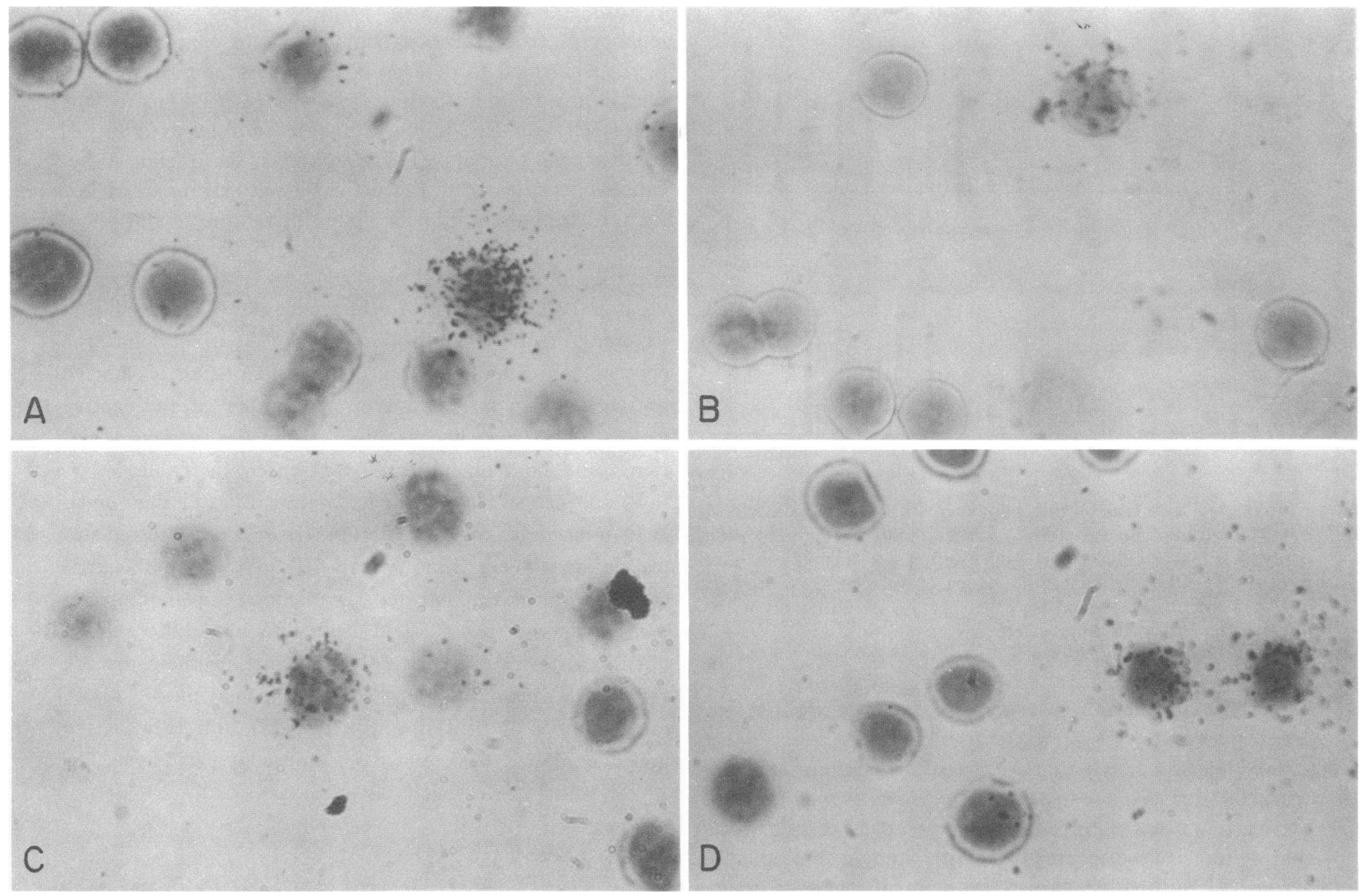

FIGURE $6{ }^{125} \mathrm{I}$-anti-IgE autoradiographs developed after a 24-h exposure. The microscope was focused on the radioactive grains overlying basophils. A-C, urticaria subjects who release less than $10 \%$ of the total available leukocyte histamine on challenge with anti-IgE; $\mathrm{D}$, normal control subject who releases over $70 \%$ of the total available leukocyte histamine on challenge with anti-IgE.

as a basic biochemical defect resulting in localized cutaneous histamine release.

We have confirmed the observation of Greaves et al. (10) that circulating basophils from patients with chronic, undifferentiated urticaria release less histamine on the average than those of control subjects when chal-

TABLE V

Autoradiograph Grain Count*

\begin{tabular}{lcrrr}
\hline & \multicolumn{5}{c}{ Number of grains/basophil } \\
Subject & $\mathbf{0 - 1 0}$ & $\mathbf{1 1 - 3 0}$ & $\mathbf{3 1 - 5 0}$ & $>50$ \\
\hline Control & 1 & 2 & 13 & 14 \\
Patient 1 & 0 & 3 & 13 & 14 \\
Patient 2 & 2 & 16 & 9 & 4 \\
Patient 3 & 0 & 3 & 16 & 11 \\
\hline
\end{tabular}

* 24-h exposure.

F. Kern and L. M. Lichtenstein lenged with anti-IgE. These investigators reported that the serum $\operatorname{IgE}$ in chronic urticaria patients was higher than in controls, but not significantly so. Our results show a significant increase. Greaves et al. also showed that maximal histamine release was obtained in both patients and controls at a similar anti-IgE concentration. From these data, it was proposed that the decreased anti-IgE histamine release is due to a qualitative abnormality in the basophil leukocyte-bound $\operatorname{IgE}$ of chronic urticaria patients (10).

We have extended these observations with studies designed to investigate the mechanism and explain the unresponsiveness noted in the cells obtained from urticaria patients. This decreased average response is largely due to the previously unappreciated fact that most patients with urticaria (70\% in this group) have basophils that respond poorly $(\leq 20 \%$ histamine release) or not at all to the challenge with anti-IgE. Even 
in those who do respond, however, the average release is less than in the control group (Table III). A curious finding, previously noted in a study of ragweed-sensitive children (11), was that cells of a small percentage of healthy donors, without a history of urticaria, were also unresponsive to anti-IgE. On the basis of the studies we have carried out, we cannot differentiate the mechanism of this unresponsiveness from that of the urticaria patients.

This unresponsiveness is not due to an abnormally low number of basophils; there was no significant difference between patients and the control group, and the values of both fell into the normal range. The fact that only five patients had active lesions when studied may explain our failure to demonstrate the previously reported decrease in the number of basophils present in chronic urticaria patients $(23)$. We do not believe that the unresponsiveness is due to low concentrations of $\mathrm{IgE}$ since, in contrast to previously reported results (24), the patients had significantly higher $\operatorname{IgE}$ levels than controls.

We do not believe that the unresponsiveness is due to an abnormal $\operatorname{IgE}$. Since the assay for $\operatorname{IgE}$ is an immunoassay, this suggests that the $\operatorname{IgE}$ molecules of patients and controls are not substantially different. However, minor differences in IgE, which might affect the cell binding of this molecule, are not ruled out.

Since it has been established that mediator release in allergic conditions is controlled by the intracellular level of cyclic nucleotides (25), we examined the baseline cyclic AMP levels in cells from patients and controls. Although the average histamine release caused by anti-IgE in these patients and controls was different, there was no significant difference in the base-line leukocyte cyclic AMP levels. Analysis of responders and nonresponders without reference to group also showed no difference.

Another possible explanation for the decreased basophil histamine release in patients with chronic urticaria is that they suffer from beta adrenergic "blockade," similar to that shown in asthmatic patients, whose peripheral leukocytes, when challenged with a beta adrenergic agonist, are less responsive than those of control individuals (26). If this lesion existed in urticaria patients, mediator release would occur more easily and the state of desensitization (see below) might be more easily encountered. Studies with the beta adrenergic agonist, isoproterenol, clearly demonstrated that the response of peripheral leukocytes, in terms of percent increase in cyclic AMP levels, was not deficient in urticaria patients.

Leukocytes challenged with anti-IgE may release only $5-10 \%$ of their total available histamine. In this instance, the cell is stimulated, but the stimulus is too "weak" to provide significant mediator release. Deu- terium oxide alone does not usually result in histamine release, but markedly enhances low levels of antigen or anti-IgE-induced release in most individuals. We utilized this reagent to ascertain whether cells were being stimulated by anti-IgE. Previous studies have shown that heavy water acts late in the release sequence; various lines of evidence suggest that its enhancing ability is largely due to effects on the microtubule-associated events leading to the secretion of histamine (16). In the present study, $\mathrm{D}_{2} \mathrm{O}$ did not potentiate release from cells of patients or controls who had anti-IgEunresponsive basophils. This result may be explained either by a lack of stimulation, or by a lesion causing unresponsiveness at some point early in the sequence of release after the signal has been appreciated.

A similar type of experiment was carried out with the calcium ionophore. This antibiotic provides a general secretory stimulus in many systems (27) and, in particular, releases histamine from the leukocytes of all individuals studied (17). In fact, ionophore produces significant histamine release from leukocytes previously desensitized in vitro (17). The mechanism of release by ionophore has been described in detail: ionophore appears to bypass the early stages in the secretory process but involves the later phases of histamine release (28). The fact that after ionophore challenge, the cells from both patients and controls release an equivalent percentage of available histamine reinforces the notion that whatever the lesion may be, it is not in the late (second) stage of mediator release, but rather occurs in the early (first) stage of the secretory process, similar to the lesion producing desensitization (13). Greaves et al. reached a similar conclusion but based on experiments with $48 / 80$. In fact, their data does not bear on this conclusion, since the mechanism of $48 / 80$ histamine release in man is not known.

One explanation offered by Greaves et al. (10) for decreased anti-IgE-induced histamine release was that the IgE molecules of chronic urticaria patients might be conformationally defective. We attempted to examine this question by providing the unresponsive cells with an $\mathrm{IgE}$ antibody preparation known to be biologically active. For this, we selected serum from a patient highly sensitive to the PLA derived from honey bee venom. In every instance passive sensitization with $\operatorname{IgE}$ antiPLA and subsequent challenge with PLA (in the presence of $\mathrm{D}_{2} \mathrm{O}$ to amplify the response [29]) produced clear-cut histamine release from cells of patients and controls who had anti-IgE-responsive cells. In both patients and controls who had anti-IgE-unresponsive cells, passive sensitization was not achieved. This suggests that the deficit in responsiveness is not due to the absence of normal $\mathrm{IgE}$ in chronic urticaria patients. It does not rule out the possibility that these patients have cells that fail to bind $\operatorname{IgE}$.

Histamine Release in Urticaria 
To explore the possibility of a defective basophil IgE receptor in the nonresponding urticaria patients, ${ }^{125} \mathrm{I}-$ anti-IgE autoradiographic studies were performed. The results indicate that a significant anti-IgE-IgE interaction occurs on the surface of basophils from patients whose leukocytes do not release histamine upon antiIgE challenge. Radiolabeled grain counts were performed (Table V), but because of the small number of subjects studied, it is impossible to state that a quantitative defect in $\operatorname{IgE}$ does not exist. However, the number of grains overlying the basophils and the variability noted is consistent with previously published data concerning the number and variability of basophil IgE molecules in normal subjects (30).

The data we have presented do not, therefore, provide a clear explanation of the nature of the unresponsive cells found in urticaria patients. Our studies not only extend Greaves' et al. observations but also lead us to consider a quite different mechanism. We believe the data indicate that the decreased anti-IgE-induced histamine release observed from basophils of chronic urticaria patients is due to a defect that occurs after initial anti-IgE-IgE interaction but before the actual (secondstage) release process. Our hypothesis is that the lesion represents a biochemical abnormality early in the sequence of histamine release, comparable to the phenomenon of desensitization. It has been shown that cells subjected in vitro to low doses of antigen, or to antigen in an inappropriate medium, become activated but release only a small percentage of their histamine. When challenged later with antigen or anti-IgE, they are totally unresponsive (13). Similar results can be obtained in vivo in patients on immunotherapy for allergic rhinitis (31). In chronic urticaria, we do not suggest that the releasing-desensitizing event is necessarily immunologic. If, however, urticaria can be explained as repetitive histamine release by unknown stimuli, then a phenomenon similar to desensitization may occur (32). The basophils, having released some part of their histamine in vivo, would be unresponsive when challenged in vitro with anti-IgE. The significant difference in leukocyte histamine content between anti- $\operatorname{IgE}$ responsive and nonresponsive cells is consistent with this hypothesis.

While in most instances cells of urticaria patients remain unresponsive, in a few instances cells have been observed to respond as urticaria symptoms spontaneously subside over a period of time, an observation compatible with desensitization. Similarly, we have noted one individual whose cells were responsive at one time and later become unresponsive. This fluctuation argues for a transient biochemical lesion and distinctly argues against the presence of a permanent abnormality. There is, unfortunately, at present no "marker" that allows us to differentiate a desensitized cell from a cell unresponsive for another reason. We have no explana- tion for the few controls who have unresponsive cells. Whether they are predisposed to develop urticaria remains to be seen.

These studies, therefore, provide only a beginning in delineating the nature of chronic urticaria. This is, however, the first clear-cut biochemical difference between chronic urticaria patients and normal individuals that has been observed, and this difference exists in a mediator system that almost certainly plays a role in the pathogenesis of this disease. We have tested and ruled out several possible explanations for these unresponsive cells; we are continuing this investigation with the hypothesis that the cells are desensitized due to in vivo stimulation and mediator release.

\section{ACKNOWLEDGMENTS}

The authors wish to thank Dr. Elizabeth Gillespie, who performed the cyclic AMP determinations, Dr. N. Franklin Adkinson, Jr., who performed the serum IgE determinations, and $\mathrm{Mr}$. Michael Taggart and Dr. Teruko Ishizaka for their assistance in the autoradiographic studies. The calcium ionophore A23187 was kindly provided by Dr. R. Hamill of the Lilly Research Laboratories.

This work was supported by grants AI08270 and AI1134 from the National Institute of Allergy and Infectious Diseases, National Institutes of Health, Bethesda, Md.

\section{REFERENCES}

1. Lewis, T., and Grant, R. T. 1924. Vascular reactions of the skin to injury. II. The liberation of a histamine-like substance in injured skin; the underlying cause of factitious urticaria and of wheals produced by burning; and observations upon the nervous control of certain skin reactions. Heart. 11 : 209-265.

2. Sollman, T., and Pilcher, J. D. 1917. Endermic reactions. I. J. Pharmacol. Exp. Ther. 9: 309-340.

3. Prausnitz, D., and Küstner, H. 1962. Appendix B. Studies on supersensitivity. In Clinical Aspects of Immunology. P. G. H. Gell and R. R. A. Coombs, editors. Blackwell Scientific Publications, Ltd., Oxford. 808-816.

4. Thompson, J. S. 1968. Urticaria and angioedema. Ann. Intern. Med. 69: 361-380.

5. Majno, G., and G. E. Palade. 1961. Studies on inflammation. I. The effect of histamine and serotonin on vascular permeability: an electron microscope study. J. Biophys. Biochem. Cytol. $11: 571-605$.

6. Sparrow, E. M., and D. L. Wilhelm. 1957. Species differences in susceptibility to capillary permeability factors: histamine, 5-hydroxytryptamine, and compound 48/80. J. Physiol. (Lond.). 137: 51-65.

7. Mitchell, J. C., and R. Krell. 1964. A study of the cutaneous effects of bradykinin. J. Invest. Dermatology. 43: $177-180$.

8. Herxheimer, A. 1963. The bradykinin wheal and flare in human skin. J. Physiol. (Lond.). 166: 36P. (Abstr.)

9. Lepow, I. H., W. Dias Da Silva, and J. W. Eisele. 1968. Nature and biological properties of human anaphylatoxin. In Biochemistry of the Acute Allergic Reactions. K. F. Austen and E. L. Becker, editors. F. A. Davis Company, Philadelphia. 265-282.

10. Greaves, M. W., V. M. Plummer, P. McLaughlan, and D. R. Stanworth. 1974. Serum and cell bound IgE in chronic urticaria. Clin. Allergy. 4: 265. 
11. Lichtenstein, L. M., D. A. Levy, and K. Ishizaka. 1970. In vitro reversed anaphylaxis: characteristics of antiIgE mediated histamine release. Immunology. 19: 831842.

12. Ishizaka, K., T. Ishizaka, and E. H. Lee. 1970. Biologic function of the $\mathrm{Fc}$ fragments of $\mathrm{E}$ myeloma protein. Immunochemistry. $7:$ 687-702.

13. Lichtenstein, L. M., and A. G. Osler. 1964. Studies on the mechanisms of hypersensitivity phenomena. IX. Histamine release from human leukocytes by ragweed pollen antigen. J. Exp. Med. $120: 507-530$.

14. May, C. D., M. Lyman, R. Alberto, and J. Cheng. 1970. Procedures of immunochemical study of histamine release from leukocytes with small volume of blood. $J$. Allergy. 46: 12-20.

15. Shore, P. A., A. Burhalter, and V. H. Cohn, Jr. 1959. A method for the fluorometric assay of histamine in tissues. J. Pharmacol. Exp. Ther. 127: 182-186.

16. Gillespie, E., and L. M. Lichtenstein. 1972. Histamine release from human leukocytes: studies with deuterium oxide, colchicine, and cytochalasin B. J. Clin. Invest. 51 : 2941-2947.

17. Lichtenstein, L. M. 1975. The mechanism of basophil histamine release induced by antigen and by the calcium ionophore A23187. J. Immunol. 114: 1692-1699.

18. Wide, L. 1971. Solid phase antigen-antibody systems. In Radioimmunoassay Methods. K. E. Kirkham and W. M. Hunter, editors. E. and S. Livingstone, Ltd., Edinburgh. 405-412.

19. Brown, B. L., D. M. Albano, R. P. Elkins, and A. M. Sgherzi. 1971. A simple and sensitive saturation assay method for the measurement of adenosine $3^{\prime}: 5^{\prime}$-cyclic monophosphate. Biochem. J. 121: 561-562.

20. Levy, D. A., and A. G. Osler. 1966. Studies on the mechanism of hypersensitivity phenomena. XIV. Passive sensitization in vitro of human leukocytes to ragweed pollen antigen. J. Immunol. 97: 203-212.

21. Ishizaka, T., R. DeBernardo, H. Tomioka, L. M. Lichtenstein, and K. Ishizaka. 1972. Identification of basophil granulocytes as a site of allergic histamine release. J. Immunol. 108: 1000-1008.
22. Ishizaka, T., H. Tomioka, and K. Ishizaka. 1971. Degranulation of human basophil leukocytes by anti- $\gamma \mathrm{E}$ antibody. J. Immunol. $106:$ 705-710.

23. Rorsman, H. 1962. Basophilic leukopenia in different forms of urticaria. Acta Allergol. 17 : 168-184.

24. Juhlin, L., S. G. O. Johansson, H. Bennich, C. Högman, and $\mathrm{N}$. Thyresson. 1969. Immunoglobulin $\mathrm{E}$ in dermatoses. Levels in atopic dermatitis and urticaria. Arch. Dermatol. 100 : 12-16.

25. Lichtenstein, L. M., and H. R. Bourne. 1971. Inhibition of allergic histamine release by histamine and other agents which stimulate adenyl cyclase. In Second International Symposium on the Biochemistry of Acute Allergic Reactions. K. Frank Austen and E. L. Becker, editors. Blackwell Scientific Publications Ltd., Oxford. 161-174.

26. Parker, C. W., and J. W. Smith. 1973. Alterations in cyclic adenosine monophosphate metabolism in human bronchial asthma. I. Leukocyte responsiveness to $\beta$ adrenergic agents. J. Clin. Invest. 52: 48-59.

27. Cochrane, D. E., and W. W. Douglas. 1974. Calciuminduced extrusion of secretory granules (exocytosis) in mast cells exposed to $48 / 80$ or the ionophores A23187 and X-537A. Proc. Natl. Acad. Sci. U. S. A. 71: 408412.

28. Lichtenstein, L. M. 1971. The immediate allergic response: in vitro separation of antigen activation, decay, and histamine release. J. Immunol. 107: 1122-1130.

29. Ishizaka, K. 1974. IgE to date. Advances in Asthma and Allergy. Fisons Corporation, Bedford, Mass. 1(No. 2): 1-5.

30. Ishizaka, T., C. S. Soto, and K. Ishizaka. 1973. Mechanisms of passive sensitization. III. Number of IgE molecules and their receptor sites on human basophil granulocytes. J. Immunol. 111: 500-511.

31. Lichtenstein, L. M., and D. A. Levy. 1972. Is "desensitization" for ragweed hay fever immunologically specific? Int. Arch. Allergy Appl. Immunol. 42: 615-626.

32. Baxter, J. H., and R. Adamik. 1975. Control of histamine release: effects of various conditions on rate of release and rate of cell desensitization. J. Immunol. 114: 1034-1041. 